\title{
Interculturalidad y Cooperativismo. Doctrina. Legislación. Experiencia
}

\author{
Dante Cracogna
}

Universidad de Buenos Aires

\section{Introducción}

El objeto del presente trabajo apunta a la consideración del cooperativismo como una expresión de las relaciones sociales y económicas que toma en cuenta y privilegia a las personas en cuanto tales, sin atender a su condición racial, económica, cultural, política o religiosa y cómo esa característica se traduce en la legislación sobre cooperativas de los países de América Latina. Finalmente, como evidencia empírica se abordará sucintamente el caso de la Argentina, poniendo de relieve este rasgo esencial del cooperativismo en la experiencia de un país de inmigración.

\section{Orígenes de las cooperativas}

Las cooperativas —en el sentido moderno y actual del vocablotuvieron su origen en diversos países europeos a mediados del siglo XIX. Así aparecieron las primeras cooperativas de consumo en Inglaterra, de crédito y de comercialización agraria en Alemania y de trabajo en Francia, para mencionar solamente los casos más relevantes y que tuvieron mayor resonancia histórica. ${ }^{1}$

Parecería obvio señalar que en esa época y en el ambiente de cada una de esas experiencias primigenias de carácter eminentemente local

1 W.P. WATKINS: El movimiento cooperativo internacional, trad. Dolly Simmons, Intercoop, Buenos Aires (1977), pp. 20 y ss. 
y reducidas en sus alcances, las urgencias que se planteaban a quienes recurrían a la organización cooperativa para solucionarlas no tenían que ver con problemas de diferencias raciales, culturales o políticas. En todo caso, las dificultades que se planteaban eran de orden económico y social del grupo en cuestión y las cooperativas pugnaban por superarlas para que sus miembros pudieran acceder a mejores niveles de vida; pero —en general — no existían en el medio en que nacieron las cooperativas cuestiones de naturaleza cultural, racial o religiosa pues los colectivos que formaban esas cooperativas estaban dotados de una relativa homogeneidad en tales aspectos. ${ }^{2} \mathrm{Y}$ el enemigo común al que debían hacer frente era el estado de necesidad económica.

De esa suerte, las distintas cooperativas se diferenciaron por su objetivo inmediato conforme con el cual se determinaban sus actividades específicas (consumo, crédito, trabajo) pero todas ellas exhibían un alto grado de uniformidad entre sus miembros, lo cual las colocaba al margen de las diferencias culturales, raciales o de credos políticos o religiosos.

No obstante, en la fundamentación ideológica de las primeras experiencias cooperativas ya anidaba la preocupación por estos temas. Así, en el caso de Inglaterra, el pensamiento cooperativo pre-rochdaleano se había interesado en la cuestión. En uno de los congresos realizados por las cooperativas que inspiró el Dr. William King en 1832 se aprobó que «como el mundo cooperativo agrupa personas de todas las sectas religiosas y de todos los partidos políticos, se acuerda por unanimidad que los cooperadores, en cuanto tales, no se encuentran identificados con ningún dogma religioso, irreligioso o político.» ${ }^{3}$ Esta demostración de amplitud y tolerancia no obstaba al profundo sentimiento cristiano de King, quien consideraba el espíritu y la ética evangélicos como los del movimiento cooperativos. Por su parte, Robert Owen, considerado por muchos como el fundador del socialismo bri-

2 Gromoslav Mladenatz: Historia de las doctrinas cooperativas, trad. Carmelo Tumino, Intercoop, Buenos Aires, pp. 63 y ss.

3 Paul LAMBERT: La doctrine cooperative, Las Propagateurs de la Coopération, Bruxelles (1959), p. 30. Las ideas del Dr. King acerca de la cooperación se encuentran en el periódico The Co-operator que publicó entre 1828 y 1830, reproducido en T.W. Mercer: Co-operation's Prophet, Co-operative Union Ltd., Manchester (1947). 
tánico e inspirador de las cooperativas de ese país, promovió una serie de congresos cooperativos previos a la experiencia de Rochdale. En el congreso realizado en Halifax en 1835 fundó la Asociación de Todas las Clases de Todas las Naciones que expresa de manera incontrastable su vocación universalista. ${ }^{4}$

De igual manera pueden mencionarse las ideas de Saint-Simon y de Fourier $^{5}$, precursores de la cooperación en Francia, quienes proclamaban también la universalidad de la solución cooperativa y otro tanto puede afirmarse de Friedrich W. Raiffaisen, quien inspiró y organizó las cooperativas rurales de crédito en Alemania sobre la base de sus ideas cristianas. ${ }^{6}$

De tal suerte que en el pensamiento cooperativo pre-rochdaleano se encuentra ya contenido un profundo sentido universalista de la cooperación, aun cuando las primeras experiencias cooperativas tuvieron un arraigo y objetivo de carácter eminentemente local. ${ }^{7}$

\section{Los principios cooperativos}

El congreso fundacional de la Alianza Cooperativa Internacional (ACI) celebrado en Londres en 1895 aprobó una serie de resoluciones en base a las cuales debía elaborarse el estatuto de dicha organización entre las que se contaba la promoción de relaciones económicas entre las cooperativas de todas las naciones y la no interferencia en mate-

4 Arnold Bonner: British Co-operation, Co-operative Union Ltd., Manchester (1961), p. 37.

5 Henri DesRoche: Le project coopératif, Les Éditions Ouvrières, Paris (1976), p. 40.

6 Franz Braumann: Raiffeisen, trad. Rafael Mondragón, Confederación Mexicana de Cajas Populares, San Luis Potosí (1988), passim.

7 Watkins lo expresa adecuadamente: «El movimiento cooperativo internacional representa una idea que sirve de inspiración a toda la humanidad... Así, la cooperación como expresión constructiva del ancestral instinto de ayuda mutua mantiene la esperanza. Ofrece a hombres y mujeres una línea clara de pensamiento y acción que lleva, paso a paso, de la asociación con los vecinos más próximos y compañeros de trabajo a relaciones de ayuda mutua con otros hombres y mujeres en los más lejanos confines del mundo» (W.P. WATKINS: El movimiento cooperativo internacional, cit., cuya introducción y primeros capítulos brindan una magnífica visión de la internacionalidad del cooperativismo). 
ria política y religión. ${ }^{8}$ En consecuencia, el artículo 2 del estatuto aprobado en el Congreso de 1896 estableció que la $\mathrm{ACI}$ no se involucra en esas cuestiones y que «la cooperación es un terreno neutral en el que las personas de las más variadas opiniones y que sienten las más diversas necesidades pueden encontrarse y trabajar en común. Para mantener esta neutralidad, de la cual depende la unidad del movimiento cooperativo, cada persona y asociación afiliada a la Alianza reconoce que la cooperación es autosuficiente y no debe servir de instrumento de ningún partido. $»^{9}$

La primera definición formal de los principios cooperativos, realizada en el Congreso de la ACl celebrado en París en 1937, incorpora claramente principios orientados a garantizar la naturaleza universal del cooperativismo. La adhesión libre, el gobierno democrático y la promoción de la educación constituyen expresión cabal de ese afán. Empero, existe un principio que lo manifiesta de manera categórica y sin ambages: el que prescribe la neutralidad política y religiosa de las cooperativas. ${ }^{10}$ Queda, pues, comprendido en el entramado doctrinario del cooperativismo el espíritu amplio, humanista y ecuménico que lo anima de una forma que no resulta de un mero enunciado aislado sino de la articulación de sus distintos principios fundamentales.

Cuando la $\mathrm{ACI}$ reformuló los principios cooperativos en su XXIII Congreso realizado en Viena en 1966, el sentido intercultural del cooperativismo se afianzó, pese a que el enunciado de la neutralidad política y religiosa ya no figuró como un principio separado. En efecto, en el enunciado del primer principio sobre la adhesión voluntaria y abierta se incorpora un párrafo final que prescribe: "no debe haber restricciones artificiales ni discriminaciones sociales, políticas o religiosas». Con ello se ratifica el sentido universal de la cooperación por la apertura del ingreso sin restricciones, con la sola exigencia de que

8 William Pascoe WATKIns: The International Co-operative Alliance 1895-1970, International Co-operative Alliance, London (1970), p. 40.

9 Idem, p. 49.

10 Alliance Coopérative Internationale: Compte Rendu du Quinzième Congrès de I'Alliance Coopérative Internationale à Paris du 6 au 9 Septembre 1937, London (1938), p. 185. A pesar de que la comisión especial que presentó el informe sobre la aplicación de los principios cooperativos destacó la importancia que las cooperativas asignaban a la neutralidad política y religiosa, señaló que ella no constituía una condición para el ingreso a la $\mathrm{ACl}$, tal vez para evitar el alejamiento de algunas organizaciones miembros. 
los que ingresen lo hagan voluntariamente y acepten las responsabilidades inherentes a su afiliación. ${ }^{11}$

La nueva formulación ratifica el gobierno democrático y, por otra parte, enfatiza que la educación debe abarcar tanto los aspectos económicos como democráticos de las cooperativas, con lo que explicita otra dimensión del papel transformador de la educación proyectándola hacia la profundización de la democracia. Empero, una significativa incorporación de la declaración de 1966 es el sexto principio, llamado de la «integración cooperativa» o de la cooperación entre cooperativas, el cual viene a ensanchar el horizonte de la interculturalidad del cooperativismo al establecer que las cooperativas deben colaborar, por todos los medios posibles, con otras cooperativas en los niveles local, nacional e internacional. Se proyecta de esa manera la acción cooperativa al plano internacional reconociéndole un definido sentido universal acorde con su naturaleza humanista y democrática. Queda así claramente definido que el cooperativismo no tiene fronteras de ninguna clase. ${ }^{12}$

El tercer momento en la evolución histórica de los principios cooperativos está marcado por la Declaración de Identidad Cooperativa aprobada por el Congreso del Centenario de la ACI realizado en Manchester en $1995 .{ }^{13}$ En ella se ratificó el alcance universal del cooperativismo de manera expresa al establecer que las cooperativas están abiertas a todas las personas capaces de utilizar sus servicios y dispuestas a aceptar las responsabilidades de ser socios, «sin discrimina-

11 International Co-operative Alliance: Twenty-third Congress. Agenda and Reports. Vienna $5^{\text {th }}$ to $8^{\text {th }}$ september 1966, Amsterdam (1966), p. 85. En el respectivo informe la comisión expone las razones por las que no incluye a la neutralidad política y religiosa como un principio autónomo y concluye destacando la «necesidad primordial de promover en todos los niveles la unidad entre los cooperativistas que es indispensable para asegurar el éxito de la misión del movimiento cooperativo» (idem, p. 78).

12 Afirma Watkins: «El hecho de que el movimiento cooperativo haya alcanzado extensión mundial significa que su futuro desarrollo deberá tener lugar cada vez más a lo largo de líneas de más estrecha y fuerte integración de sus múltiples fragmentos» (William Pascoe Watkins: Co-operative Principles Today and Tomorrow, Holyoake Books, Manchester (1990), p. 35).

13 Esta declaración fue precedida por un amplio estudio acerca de los valores cooperativos cuyo informe final fue considerado en el Congreso de la $\mathrm{ACl}$ realizado en Tokio en 1992, en el cual se destaca la importancia de la internacionalización cooperativa (Sven Ake Böök: Co-operative Values in a Changing World, International Co-operative Alliance, Geneva (1992), pp. 182 y ss). 
ción social, política, religiosa, racial o de sexo.» Es decir, que deliberadamente se extendió el enunciado del primer principio incluyendo la prohibición de discriminación racial o de género, solamente implícita en los enunciados anteriores.

Pero, significativamente, la Declaración de Manchester incorporó un nuevo principio - «interés por la comunidad»-que prescribe que las cooperativas a la vez que procuran satisfacer las necesidades y aspiraciones de sus miembros, «trabajan para conseguir el desarrollo sustentable de sus comunidades». Este principio viene a hacer explícito que las cooperativas no agotan su cometido y finalidad mediante la satisfacción de las necesidades de sus integrantes - lo cual constituye, obviamente, su primer objetivo- sino que realizan una acción en pro de la comunidad en general. Vale decir que se orientan a lograr que toda la comunidad, sin discriminación en cuanto a quienes la conforman, alcance un mayor grado de desarrollo. ${ }^{14}$

A lo largo del tiempo y en forma sostenida, la doctrina de las cooperativas ha mantenido y reforzado la vocación universalista, condenando la discriminación de cualquier clase, por una parte y, por otra, afirmando positivamente el trabajo en pos de la integración plena de la comunidad y su proyección allende las fronteras nacionales.

\section{La legislación cooperativa en América Latina}

En general, las leyes de cooperativas de los países latinoamericanos, se pliegan fielmente a los principios cooperativos proclamados por la $\mathrm{ACl}$, lo cual puede considerarse un rasgo distintivo de la legislación regional con independencia de los matices propios de cada país. Más aun, esa característica ha tendido a intensificarse en los últimos años, tal como lo demuestra la mayoría de las leyes sancionadas en época reciente.

En prácticamente todas esas leyes, el rasgo de la interculturalidad, basado en la apertura, la neutralidad, la no discriminación, la democracia, la educación, la integración y la preocupación por la comunidad, se encuentran presentes con mayor o menor intensidad.

14 Ian Mac Pherson: Co-operative Principles for the 21st Century, International Co-operative Alliance, Geneva (1995), p. 30. 
La más antigua de las leyes de cooperativas de la región en vigencia, la ley boliviana de 1958, sólo se limita a establecer el principio de gobierno democrático con un voto por socio (art. 1, inc. 2) e igualdad de derechos de todos ellos (art. 65), disponiendo que deben extender los beneficios de la educación cooperativa a toda la comunidad (art. 1, inc. 4) y contiene una limitación de corte clasista: «las sociedades cooperativas no podrán formar parte de organizaciones antisindicales o contrarias al interés de las clases trabajadoras...» (art. 13), única en la región. En cambio, otra ley antigua de la región, la N. ${ }^{\circ} 127$ de 1964 de la República Dominicana, impone que las cooperativas apliquen «las bases universales del cooperativismo conocidas como principios de Rochdale» (art. 1, inc. h), con lo cual remite a la declaración de la $\mathrm{ACl}$ de París 1937, a la sazón vigente, si bien una interpretación dinámica de la norma podría llevar la referencia a los principios de Rochdale que estuvieran vigentes en cada momento histórico, no cristalizada en la época de sanción de la ley. De esa suerte adopta un amplio criterio no discriminatorio.

Entre la legislación de un período intermedio cabe mencionar la ley argentina 20.337 de 1973, la cual prohíbe expresamente que las cooperativas tengan como fin principal ni accesorio la propaganda de ideas políticas, religiosas, de nacionalidad, región o raza o impongan condiciones de admisión vinculadas con ellas (art. 2, inc. 7), como así también prohíbe imponer límite al número de asociados (art. 2, inc. 2), cuyo ingreso es libre (art. 17), a todos los cuales reconoce un solo voto, sin ventaja ni privilegio para ninguno (art. 2, inc., 3) y establece el fomento de la ecuación y la integración cooperativas. De igual manera, la ley brasileña 5.764 de 1971 reconoce la adhesión libre y el número ilimitado de asociados como también la neutralidad política y la no discriminación religiosa, racial y social (art. 4, incs. I, II y IX). La ley guatemalteca de 1978 acoge los principios cooperativos vigentes en esa época, entre los cuales prescribe específicamente la neutralidad política y religiosa de las cooperativas (art. 4 , inc. d).

Por su parte, la ley panameña 38 de 1980 incorpora los principios entonces vigentes y dispone que la adhesión a las cooperativas será «abierta y voluntaria, sin ninguna discriminación social, política, racial o religiosa» (art. 2, inc. a), además de consagrar el gobierno democrático, la igualdad de los asociados, el fomento de la educación y la integración cooperativa. La ley costarricense de 1982 determina que las cooperativas deben observar neutralidad racial, religiosa y política, 
además de imponerles libre ingreso de asociados, con un solo voto cada uno, fomento de la educación y promoción de la integración cooperativa (art. 3). En el caso de Colombia, la Ley 79 de 1988 establece el ingreso libre e ilimitado de socios, el gobierno democrático, la educación y la integración cooperativas (art. 5), a los que agrega expresamente la prohibición de «establecer restricciones o llevar a cabo prácticas que impliquen discriminaciones sociales, económicas, religiosas o políticas» (art. 6, inc. 1).

La ley paraguaya 438 de 1994 recoge fielmente los principios cooperativos tal como se encontraban enunciados por el Congreso de la $\mathrm{ACl}$ de Viena 1966. En la materia que aquí interesa cabe señalar que el art. 4 inc. e) establece la neutralidad de las cooperativas «en materia política partidaria y movimentista, religión, raza y nacionalidad», lo cual brinda amplitud al tema. Además dispone la adhesión voluntaria; el gobierno democrático; la igualdad de derechos de los socios y la ilimitación de su número; la educación y la integración cooperativa.

La Ley General de Sociedades Cooperativas de México (1994) impone a las cooperativas el «respeto al derecho individual de los socios de pertenecer a cualquier partido político o asociación religiosa» (art. 6, inc. VI). Además exige libertad de asociación, fomento de la educación y participación en la integración, pero prescribe que los extranjeros — si bien pueden ser socios cumpliendo determinados requisitos - «no podrán desempeñar puestos de dirección o administración en las sociedades cooperativas» (art. 7). Esta última disposición no se encuentra en otras legislaciones del Continente.

En la legislación más reciente, la Ley Especial de Asociaciones Cooperativas de Venezuela de 2001 incorpora de manera prácticamente textual los valores y los principios cooperativos tal como se hallan enunciados en la Declaración de Identidad Cooperativa de la ACI 1995. Solamente agrega a continuación del art. 4 una reivindicación de la tradición nacional: «... se guían también por los principios y criterios de las experiencias y los procesos comunitarios solidarios que son parte de nuestra cultura y recogen la tradición solidaria de nuestro pueblo.» A su vez, la ley chilena de 2003 establece la igualdad de derechos y obligaciones de los socios con ingreso voluntario y un solo voto por persona y específicamente dispone que las cooperativas deben observar neutralidad política y religiosa y desarrollar actividades de educación cooperativa (art. 1). Por su parte, la Ley General de 
Cooperativas de Nicaragua N. ${ }^{\circ} 499$ de 2004, dispone el libre ingreso de asociados y el gobierno democrático con un voto por asociado (art. 8. $^{\circ}$ incs. a) y c)). Impone asimismo la ilimitación del número de asociados y la neutralidad y no discriminación (art. 11, incs. a) y d)).

En suma, la legislación latinoamericana sobre cooperativas en general acoge de forma expresa disposiciones que consagran la interculturalidad del cooperativismo y aun en los pocos casos en que no lo hace expresamente, tal condición surge inequívocamente del plexo normativo que caracteriza a estas entidades.

\section{Una lección de la experiencia}

Como colofón resulta de interés mencionar un caso concreto de la experiencia regional en el que se puso de manifiesto en forma elocuente la interculturalidad del cooperativismo, contribuyendo eficazmente a la integración social de un país de inmigración, especialmente en el ámbito rural. Se trata de la Argentina de fines del siglo XIX y primeras décadas del siguiente.

Es del caso recordar que al momento de organizarse políticamente el país por medio de la Constitución de 1853 la población existente era muy escasa en relación con la dilatada extensión del territorio nacional. Esa circunstancia motivó que la Constitución dispusiera la promoción de la inmigración conforme con el lema enunciado por su inspirador, Juan Bautista Alberdi: «gobernar es poblar». Como resultado de la política inmigratoria desarrollada por el gobierno nacional, a comienzos del siglo xx el 30\% de la población argentina había nacido en el extranjero. ${ }^{15}$

En ese contexto, la masiva llegada de los inmigrantes provenientes de diferentes países y culturas produjo un profundo cambio en la fisonomía del país toda vez que juntamente con la ocupación de

15 Afirma Gastón Gori: «La inmigración alcanzaba cifras tan elevadas que revistió el carácter de aluvional. ... Las colonias agrícolas, la actividad ganadera y la industrial habían creado las condiciones para que la inmigración espontánea se dirigiera a nuestras playas. Desde 1870 hasta 1890, un millón y medio de personas entraron al país, en una corriente que no se interrumpiría hasta 1913, aumentando en forma progresiva para totalizar más de tres millones» (Inmigración y colonización en la Argentina, EUDEBA, Buenos Aires (1964), p. 98). 
su territorio y la asimilación de las costumbres y el idioma locales debió producirse la integración de los recién llegados al nuevo país, a su sistema productivo y a la sociedad local. Al mismo tiempo los inmigrantes se encontraban con una realidad económica y social por completo diferente de sus países de origen y eran generalmente ubicados en lugares distantes de los centros poblados donde el aislamiento era la regla, generalmente carentes de las más elementales comodidades.

Estos nuevos pobladores traían en muchos casos alguna experiencia cooperativa de sus respectivos países, la cual resultó avivada por las necesidades del nuevo entorno. Se produjo de esa manera un importante desarrollo cooperativo que contribuyó eficazmente a hacer menos penosa la adaptación a la nueva realidad y a posibilitar su inclusión social a la vez que promover la organización más adecuada de su actividad económica. Se fue así acrisolando la población inmigratoria para lo cual la cooperativa constituyó una fragua de alto valor económico y social.

Entre las más antiguas manifestaciones del cooperativismo argentino se encuentran las desarrolladas en las colonias galesas de la Patagonia, donde las condiciones extremas del clima y la distancia empujaron a la organización cooperativa para facilitar la explotación agrícola y ganadera y el transporte y comercialización de los productos en común, además de estimular las manifestaciones de la vida social de los colonos. La Compañía Mercantil del Chubut, instalada en Puerto Madryn, constituye una muestra relevante de esta actividad. ${ }^{16}$

En la Mesopotamia se asentaron las primeras colonias de inmigrantes judíos provenientes del Volga y de otras regiones de Europa. Estas colonias estaban dedicadas al trabajo de la tierra, especialmente la producción de trigo y lino, en la provincia de Entre Ríos y allí fundaron diversas cooperativas de aprovisionamiento y comercialización, entre las que merece citarse Fondo Comunal de Domínguez, que les permitieron superar las difíciles condiciones iniciales y abrirse una

16 Según algunos autores se trata de la primera cooperativa de la Argentina, fundada en 1885 bajo la forma de una sociedad anónima cuando aun no existían disposiciones legales específicas sobre cooperativas (Domingo BÓREA: Tratado de Cooperación, Imprenta Gadola, Buenos Aires (1927), pp. 257 y ss; Néstor S. Colul: Cooperativas y pseudocooperativas argentinas anteriores a 1900, Círculo de Estudios Cooperativistas de Buenos Aires, Buenos Aires (1967), p. 21, nota 3). 
perspectiva de arraigo y progreso. ${ }^{17}$ Las cooperativas agrarias surgieron asimismo en otras comunidades de origen judío de diferentes lugares del país.

En Pigüé, localidad rural del sur de la provincia de Buenos Aires, una colonia de inmigrantes franceses provenientes de la región de Aveyron, fundó en 1898 la primera cooperativa de seguros del país para amparar a los sembrados de cereales de los riesgos del granizo. Esta experiencia se fue extendiendo a otras zonas posibilitando que los agricultores superaran las graves penurias que derivaban del fracaso de sus cosechas por razones climáticas. ${ }^{18}$

En la zona de la colonización italiana de piamonteses, lombardos y friulanos, ubicada principalmente en la provincia de Santa Fe, fueron creándose cooperativas agrarias dedicadas a la provisión de insumos y la comercialización de producción, las que asimismo facilitaban crédito y artículos de consumo a los pobladores de zonas que de otra manera no podían resolver sus necesidades primarias de subsistencia y actividad productiva. Por otro lado, esas cooperativas contribuían asimismo a facilitar la integración social de sus miembros llevando adelante acciones de desarrollo comunitario. ${ }^{19}$

La provincia del Chaco, donde se radicaron inmigrantes principalmente de origen polaco y la provincia de Misiones a donde acudieron alemanes, checos y rusos fueron también ámbitos de importante actividad cooperativa en el medio agrario. Estas cooperativas no solamente atendieron las necesidades económicas de los colonos sino que promovieron la creación de escuelas, centros de recreación, bibliotecas y otras actividades de desarrollo social de sus respectivas localidades. ${ }^{20}$

17 David Merecer: El cooperativismo de Entre Ríos y sus pioneros, Intercoop, Buenos Aires (1971), pp. 9 y ss. Una completa e interesante historia de una de las cooperativas más representativas de la colonización judía en el país se encuentra en Fondo Comunal. Cincuenta años de su vida, Fondo Comunal Sociedad Cooperativa Agrícola Limitada, Villa Domínguez (1957), passim.

18 Como curiosidad, señala Colli que los iniciadores de esta cooperativa habían pedido asesoramiento a Charles Gide para su organización (Néstor S. Colul: op. cit., p. 40).

19 Dante Cracogna: Cooperativismo agrario argentino, Intercoop, Buenos Aires (1968), pp. 41 y ss. donde se rastrean los orígenes de las primeras cooperativas agrarias del país.

20 Celestino Sienrra, Campo y ciudad. El problema agrario argentino, 2. ${ }^{a}$ ed., Rosario (1973), pp. 167-169. 
En el medio urbano la presencia cooperativa y su efecto integrador socio cultural no es susceptible de advertirse con la misma nitidez que en el ambiente rural pero no por ello es menos importante. En efecto, en las ciudades la afluencia de inmigrantes - obreros, empleados, profesionales - fue de relevante significación y también allí las cooperativas constituyeron un medio de aglutinamiento y promoción económica y social de sus miembros. ${ }^{21}$

Cabe puntualizar que las primeras disposiciones legales en materia de cooperativas fueron sólo tres artículos incorporados al Código de Comercio en virtud de la reforma realizada en 188922, cuyo contenido era insuficiente y poco adecuado a la naturaleza propia de estas entidades, lo cual no resulta sorprendente que ocurriera en el extremo sur de América Latina pues a esa altura eran pocos los países europeos que contaban con leyes de cooperativas. Habría que esperar hasta 1926 para que se dictara la Ley 11.388 que vino a establecer un régimen cabalmente adecuado para las cooperativas, cuyo texto contenía los rasgos fundamentales de ellas aun cuando la primera declaración de los principios cooperativos fuera formulada por la $\mathrm{ACI}$ recién once años más tarde. ${ }^{23}$ En el art. 2 de esta ley se consagró la adhesión libre y voluntaria, la ilimitación del número de asociados, la igualdad de derechos de todos ellos y el gobierno democrático. La neutralidad fue prescripta de una manera amplia y categórica al disponer que las cooperativas «no podrán tener por fin principal ni accesorio la propaganda de ideas políticas, religiosas, de nacionalidades o regiones determinadas, ni imponer como condición de admisión la vinculación de los socios con organizaciones religiosas, partidos políticos o agrupaciones de nacionalidades o regionales.» Esta norma tan precisa revis-

21 En la investigación de Néstor S. Colli sobre las cooperativas anteriores a 1900, ya citada, se mencionan numerosas experiencias cooperativas surgidas con activa participación de inmigrantes en el medio urbano, especialmente en la ciudad de Buenos Aires. Por su parte, Ernesto Olivier menciona a la Sociedad Cooperativa de Producción y Consumos, fundada en Buenos Aires en 1875, como la más antigua cooperativa del país (Primer intento de cooperativismo en la Argentina, Círculo de Estudios Cooperativistas de Buenos Aires, Buenos Aires (1962), passim).

22 Roberto Jorge PASTORINO: Orígenes del Derecho Cooperativo argentino, Intercoop, Buenos Aires (1998), pp. 30 y ss.

23 La evolución de la legislación cooperativa argentina está esbozada en Dante Cracogna: Estudios de Derecho Cooperativo, Intercoop, Buenos Aires (1986), pp. 56 y SS. 
tió especial significado en un país donde la inmigración alcanzaba una proporción muy alta de la población.

De manera que las primeras experiencias cooperativas en Argentina, aquéllas que contribuyeron eficazmente a integrar a los inmigrantes de diferentes culturas para construir un único país a partir de su diversidad, fueron realizadas aun antes de que la legislación se hiciera cargo específicamente de la interculturalidad del cooperativismo. Fue la propia virtualidad del cooperativismo la que hizo posible esa realidad. 